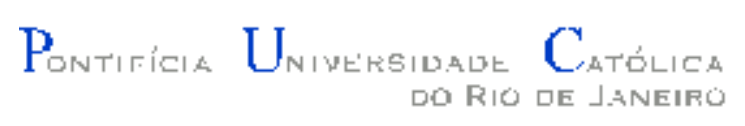

Mariana Figueiredo Massotti

\title{
A Igreja Nossa Senhora do Rosário e São Benedito dos Homens Pretos no Rio de Janeiro
}

\begin{abstract}
Dissertação do programa de Pós-graduação
Dissertação apresentada para final de curso de especialização em História da Arte e Arquitetura no Brasil
\end{abstract}

Orientador: Prof. César Augusto Tovar Silva 


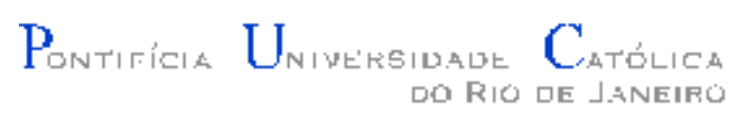

Mariana Figueiredo Massotti

\section{A Igreja Nossa Senhora do Rosário e São Benedito dos Homens Pretos no Rio de Janeiro}

Dissertação apresentada como requisito parcial para a conclusão do curso de especialização pelo Programa de Pós-graduação em História da Arte e da Arquitetura no Brasil da PUC-Rio. Aprovada pela Comissão Examinadora abaixo assinada.

Prof. Cesar Augusto Tovar Silva Orientador Departamento de Historia - PUC-Rio

Prof. Antônio Edmilson Martins Rodrigues Departamento de História - PUC- Rio

Profo João Masao Kamita

Orientador

Departamento de História-PUC-Rio

Rio de Janeiro, novembro de 2015 
Todos os direitos reservados. É proibida a reprodução total ou parcial do trabalho sem autorização da universidade, da autora e do orientador

\section{Mariana Figueiredo Massotti}

Graduou-se em Desenho Industrial, Habilitação em Projeto de Produto pela Pontifícia Universidade Católica do Rio de Janeiro em 2010. Atualmente trabalha como produtora de arte em televisão e publicidade

Ficha catalográfica

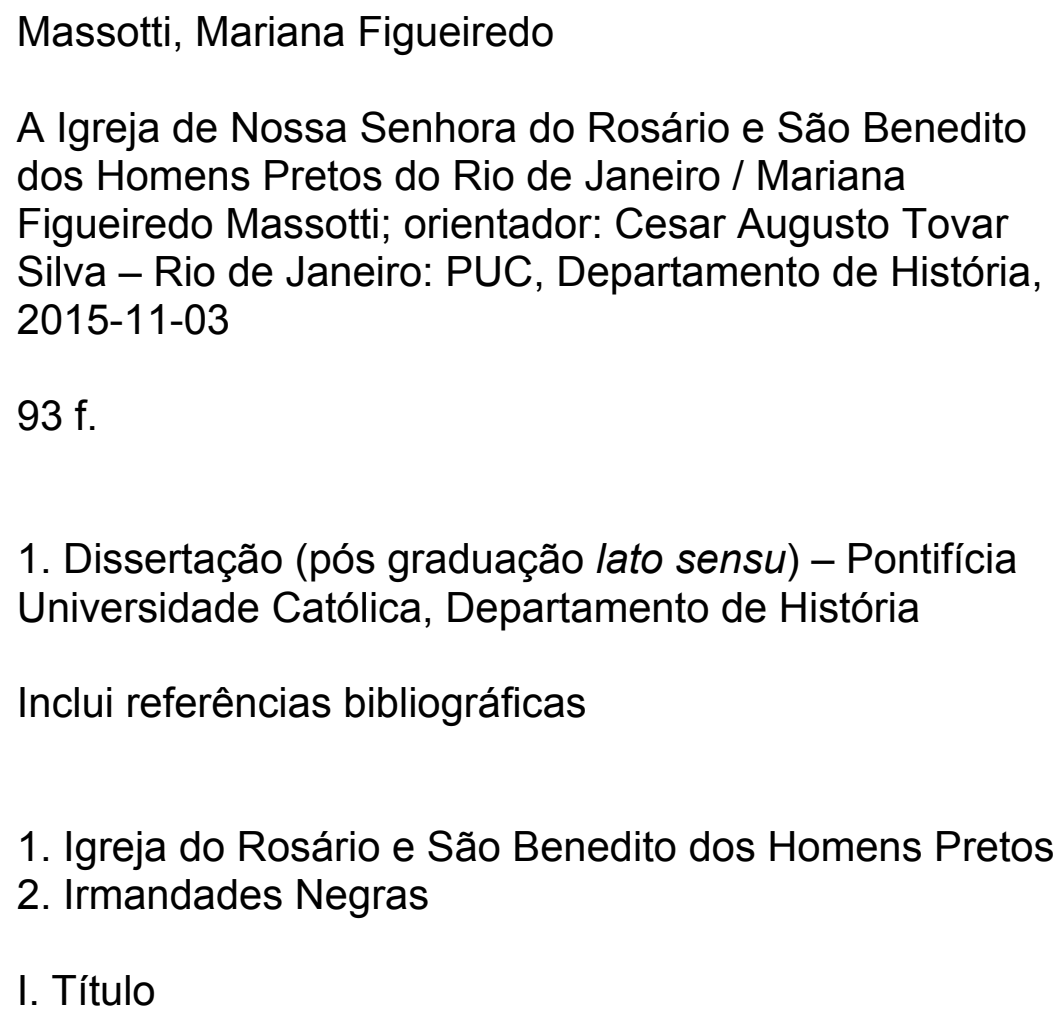

I. Título 


\section{AGRADECIMENTOS}

Agradeço primeiramente ao meu orientador, Professor Cesar Augusto Tovar Silva. Obrigada pela dedicação, correções e importantes comentários, que foram fundamentais para a realização desse trabalho.

A todos os professores que tive no curso. Agradeço o conteúdo passado para durante as aulas.

Agradeço a minha família pelo constante apoio e incentivo, em especial a minha irmã que se dispôs a ler e opinar sobre esse trabalho.

À minha amiga Ellen Lima, uma grande amizade que o curso me trouxe.

Agradeço ao Guilherme Borges e seu amigo e professor Gustavo Galvão. Obrigada pelos livros emprestados e pela atenção que tiveram em relação ao meu trabalho.

Pelo Irmão da Irmandade do Rosário Anderson Santos Ribeiro, pelas idéias trocadas e informações sobre a história da igreja.

Aos funcionários do Instituto e da biblioteca Noronha Santos, pela atenção e contribuição na pesquisa, que foi fundamental para a realização desse trabalho.

Aos professores da comissão examinadora. 
RESUMO

Massotti, Mariana Figueiredo, A Igreja de Nossa Senhora do Rosário e São Benedito dos Homens Pretos do Rio de Janeiro, Rio de Janeiro, 2015, Dissertação de pós graduação (Lato Sensu) - Departamento de História, Pontifícia Universidade Católica do Rio de Janeiro.

No Brasil colonial os escravos eram impedidos de manifestar as suas formas de cultura e religiosidade. As Irmandades voltadas para os irmãos negros, escravos ou libertos foram muito difundidas na época, pois era um dos únicos momentos que o escravo tinha para participar da sociedade. A Igreja de Nossa Senhora do Rosário e São Benedito dos Homens Pretos é um importante exemplo desse período. Presente até os dias de hoje na rua Uruguaiana, a Igreja sobrevive com muita dificuldade depois de passar por uma história de muitas lutas e tragédias.

\section{Palavra-chave}

Irmandades negras - Período colonial - Rio de Janeiro - Arquitetura 


\section{SUMÁRIO}

CAPÍTULO1

1.

Introdução. 1

CAPÍTULO 2

2. Os escravos e a Igreja católica no Brasil Colonial..............................3

2.1. Os escravos no Brasil..............................................................

2.2. Os escravos e a Igreja católica.................................................. 5

CAPÍTULO 3

3. As Irmandades religiosas no Brasil...............................................

3.1. O que eram as Irmandades e qual a sua finalidade .........................8

3.2. A devoção aos santos negros..................................................13

3.3. Como eram formadas as Irmandades....................................16

3.4. Os cargos dos irmãos nas Irmandades....................................18

CAPÍTULO 4

4. A Igreja e a Irmandade do Rosário e São Benedito dos Homens Pretos do Rio de Janeiro

4.1. A construção da Igreja de Nossa Senhora do Rosário e São Benedito dos Homens Pretos.

4.2. A Igreja é a Catedral de 1737 a 1808. 22

4.3. O Senado da Câmara se estabelece no consistório da Igreja em setembro de 1821.

CAPÍTULO 5

5. A arte e a arquitetura da Igreja de Nossa Senhora do Rosário e São Benedito dos Homens pretos.

5.1. As más administrações e os seus resultados

5.2. A Igreja antes do incêndio. 32

5.3. As artes presentes na Igreja antes do incêndio

5.4. O tombamento da Igreja pelo IPHAN 
5.5. O incêndio de 1967

.55

5.6. A reconstrução da Igreja Nossa Senhora do Rosário e São Benedito

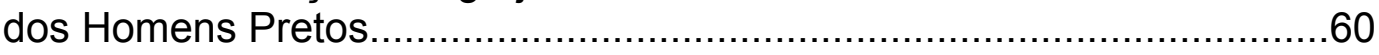

CAPÍTULO 6

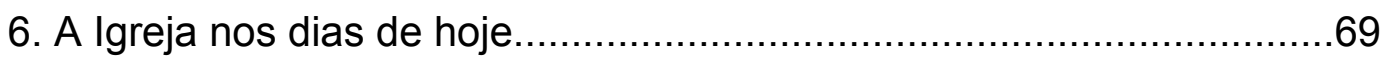

8.Imagens

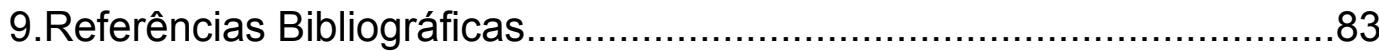

